\title{
STEPPER MOTOR ACTUATOR FOR HVAC BLEND DOOR - A REVIEW
}

\author{
ADHIRATH MANDAL ${ }^{1} \&$ HAENGMUK CHO $^{2}$ \\ ${ }^{1}$ Doctorate Student, Department of Mechanical Engineering, Kongju National University, Republic of Korea \\ ${ }^{2}$ Professor, Department of Mechanical Engineering, Kongju National University, Republic of Korea
}

Air conditioning and heating system in a car are very necessary accessory. In a general air handling system, the air duct has the heater core mounted on the evaporator core. The temperature of the air depends on the amount of mixing of the air, which passes through the heating core and then through the evaporator. The passage of air through the heater core is controlled by a flap which directs the air. In a conventional air conditioning and heating system in the car, the movement of the flap is manually. The passenger inside the vehicle adjust the flap according to their comfort. Heating, ventilation, and air conditioning (HVAC) is a type of technology which are being used extensively in vehicles, residential structures and office buildings for the environmental comfort of the human. HVAC mainly gives temperature comfort. This system also provides better indoor air. In the case of an automobile HVAC system it has all the same components which are similar to a conventional air conditioning and heating system. Only difference, the movement of the blend door are with the help of an actuator. The actuator would move the blend door constantly to mix the air between the hot air from the heating core and cold air from the evaporator to maintain the air temperature. Generally, in an HVAC door blend actuator, electro mechanical actuator is used. Electro mechanical actuator can be used in many places as they can generate motion which are mainly required by different valve actuation. The paper reviews about stepper motor being used in the actuator.
\end{abstract}

KEYWORDS: Stepper Motor, Actuator, Blend Door, HVAC \& Air Conditioner

Received: May 05, 2019; Accepted: May 25, 2019; Published: Jun 25, 2019; Paper Id.: IJMPERDAUG201934

\section{INTRODUCTION}

Air conditioning and heating system in a car are very necessary accessory. In a general air handling system, the air duct has the heater core mounted on the evaporator core. The heated coolant travels into the heating coil and then into the radiator. The heated coolant heats up the heating core and when the air passes through the heating core it gets heated up and make the cabin warm. Whereas on the other hand the air conditioning system works on a different principle. When the air conditioning is working the air does not pass through the heating core. It directly passes through the evaporator. In air conditioning the compressor pumps the refrigerant into the evaporator where it cools the air and takes up the heat from the air. The refrigerant then goes to the condenser where it cools down and is again compressed and pumped in to the evaporator. In this conventional operation of the air system the temperature of the cabin is maintained by adjusting the flow of the air through the evaporator. When maximum cooling is required the flow of air is directed totally through the evaporator and in the case of maximum heat required the air is passed through the heating core and the compressor is switched off. When the air is passed through the heating core and the compressor is switched on, it provides and mixed air in to the car passenger cabin. The temperature of the air depends on the amount of mixing of the air, which passes through the heating core and then through the evaporator. The passage of air through the heater core is controlled by a flap 
which directs the air. In a conventional air conditioning and heating system in the car, movement of the flap is manually. The passenger inside the vehicle adjust the flap according to their comfort.

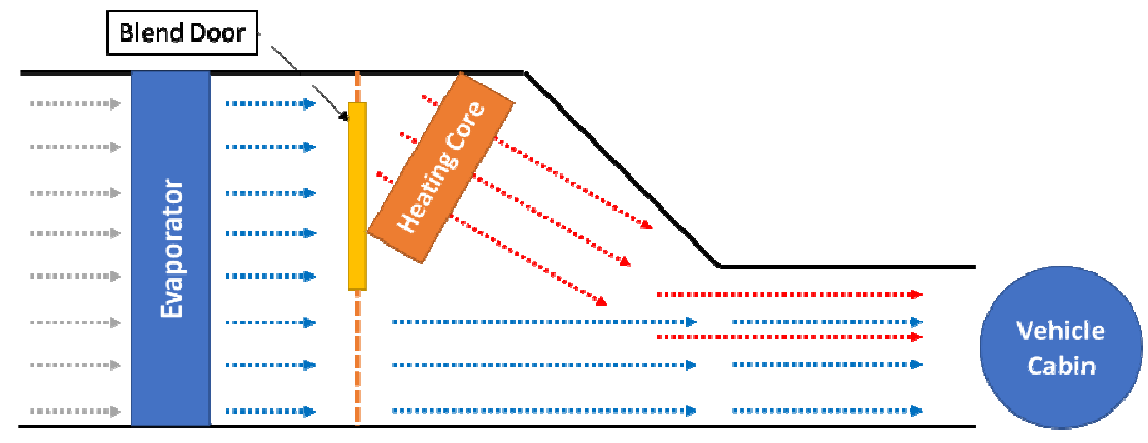

Figure 1: Conventional Air Conditioning and Heating System

Heating, ventilation, and air conditioning (HVAC) is a type of technology which are being used extensively in vehicles, residential structures and office buildings for the environmental comfort of the human. HVAC mainly gives temperature comfort. This system also provides better indoor air. HVAC controls the cabin/room temperature and humidity with the help of outside fresh air. It circulates the fresh outside air in the cabin/room with the heated or air conditioned air to maintain the humidity and the room temperate. These days the HVAC system are gaining popularity in the automobile sector. With the introduction of climate control in the automobile air conditioning system, HVAC system are becoming popular. In the case of an automobile HVAC system it has all the same components which are similar to a conventional air conditioning and heating system. Only difference, the movement of the blend door are with the help of an actuator.

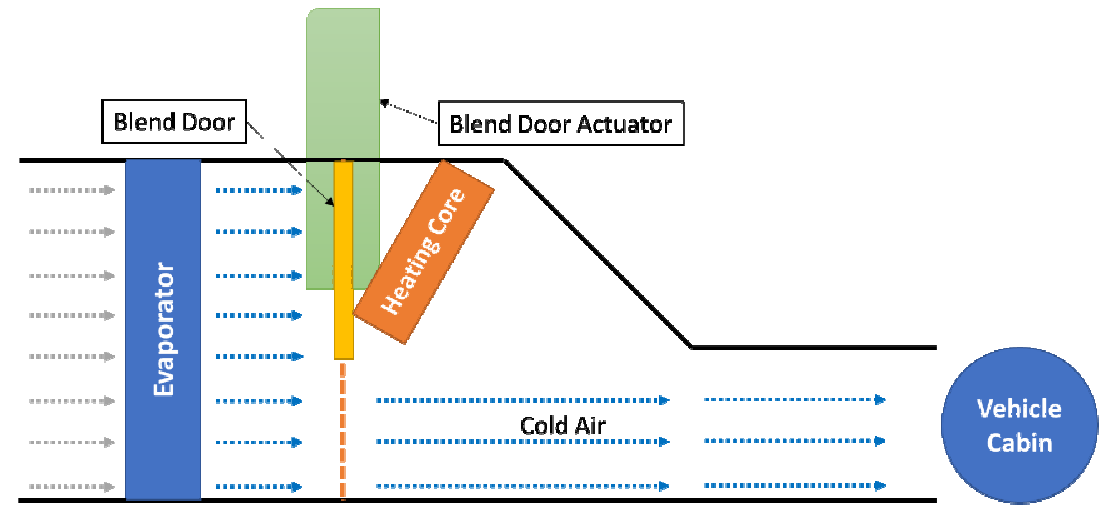

Figure 2: Blend Door Position for Cold Air

The actuator moves the blend door according to the temperature set by the passenger. It blends the hot air and the cold air to set the right amount of air temperature in the cabin of the vehicle. When cold temperature is required by the passenger the actuator moves the blend door to block the heating core, so that the air does not pass through the heating core. In the case of only hot air the blend door id shifted completely down by the actuator so that the air passes through the heating core. 


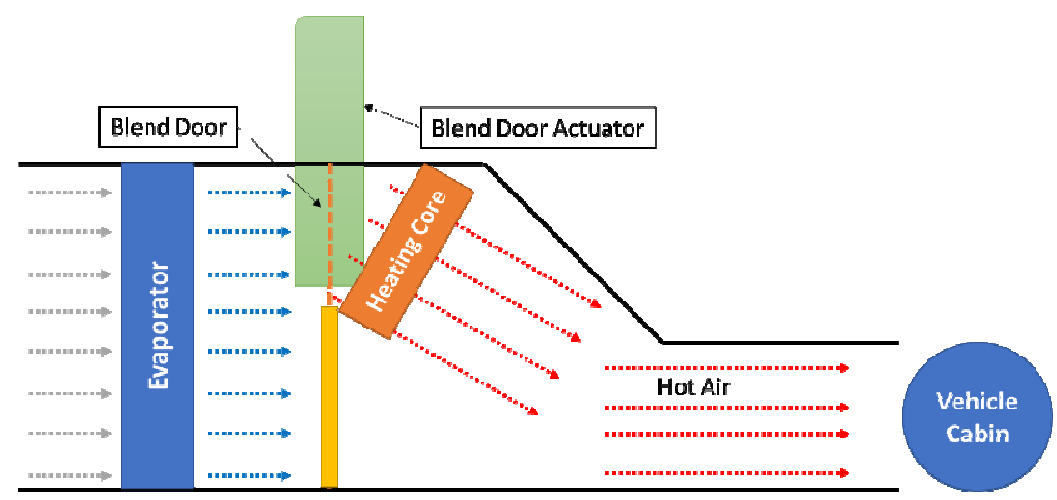

Figure 3: Blend Door Position for Hot Air

In case the passenger needs a temperature of about $25^{\circ} \mathrm{C}$ in the cabin. The actuator would move the blend door constantly to mix the air between the hot air from the heating core and cold air from the evaporator to maintain the air temperature. Temperature sensor are connected to the controller with sends signal to the actuator controller. The actuator controller reacts accordingly to move the blend door accordingly.

Actuator is a device or a functional element that connects the electronic control system (information processing part) to the nontechnical or technical process. For the control of volume, mass and energy actuators are mainly used. Power or energy are the output from an actuator, and generally it is mechanical working. Electrical power of low quantity are used for actuator control. Energy controller is required in an actuator because it controls the flow of energy and matter. This is another reason the actuator are connected in series to an energy converter or energy controller 1. Actuator can be categorised in 6 different types [2].

- Piston Actuator

- Electro Pneumatic Actuator

- Electro Mechanical Actuator

- Electro Hydraulic Actuator

- Vane Actuator

- Diaphragm Actuator

Generally, in an HVAC door blend actuator, electro mechanical actuator is used. Electro mechanical actuator can be used in many places as they can generate motion which are mainly required by different valve actuation. The actuator could produce different motions like multi turn, full $360^{\circ}$ turn, partial $\left(45^{\circ}, 90^{\circ}, 180^{\circ}, 270^{\circ}\right)$ turn or linear motion. Generally, an actuator has the following components. Firstly an electric motor which has high torque and low inertia. The motor could be a single phase or dc. Secondly a gear mechanism, this helps in reducing the speed and increasing the torque. Thirdly a changeover mechanism which would allow the actuator to be operated manually as well as by the controller. The change over mechanism should have a locking function, this would help in stopping the actuator from being driven simultaneously2. Blend door actuator have been using electric motor for the movement of the blend door. Stepper motor could be used in the actuator for the movement of the blend door. Brushless synchronous electric motor is also known as stepper motor. The stepper motor converts the digital electrical pulses into mechanical rotation. In a stepper motor the rotation of the motor are divided into many steps. In many cases there are 200 steps. 
In each electrical pulse the stepper motor rotates one step. As the motor only rotates at a particular angle for one electric pulse, therefore there is no need for any feedback system. The stepper motor could be used in open loop system. Stepper motor are mainly of two types. Firstly, the variable reluctance stepper motor and secondly the permanent magnet stepper motor. The variable reluctance stepper motor has a stator and a soft iron rotor. It does not have a permanent magnet. Where as in the case of a permanent magnet stepper motor the rotor is made of permanent magnet and the stator is of soft iron 3 .

The stepper motor has many advantages.

- In the case of energized winding, there is full torque in the motor

- Angle of rotation is fixed by the input pulse, therefore can be used in open loop condition

- Because of fixed rotation angle it has good position control, accuracy and repeatability.

- Stepper motor has better life because of the brushless contact. Therefore, wear and tear are less and the only part on with the life depends are the bearing

- Wide range of speed could be attained by modulating the input pulse frequency.

- Stepper motor has no inertia, therefore starting, reversing and stopping response are excellent

Therefore, using stepper motor in the blend door actuator would help in increasing the life and durability. The stepper motor in the actuator would also remove the use of feedback system. It would also provide excellent accuracy to the movement of the blend door; which intern would help the HVAC system to maintaining proper cabin temperature/environment.

\section{LITERATURE REVIEW}

Kiran R. Kambly et al.4studied the plug-in electric vehicle and the energy consumption by heating, ventilation and air conditioning system (HVAC). As the PHEV have a limited energy storage the HVAC could reduce the range in condition of maintaining the cabin environment. It was seen that the cabin conditions was controlled by factors like humidity, ambient temperature, radiation from sun and trip length. An approach were developed to connect usage conditions and HVAC technologies for the consumer centric metrics which would include energy consumption and range for vehicle performance. Stochastic and transient inputs were considered for the HVAC model energy consumption in which solar loads, charging behaviour, weather conditions and driving behaviour and passenger population. The results in the study helped in apprehending the advantages and disadvantages of HVAC associated with passenger fleet electrification. It was suggested to improve the HVAC energy consumption which would improve the effectiveness of the electric vehicle. Wooyoung Jung et al.5researched about the heating, ventilation and air-conditioning system. It was found that the HVAC system consumes almost half of the energy in the buildings energy. With technological advancements the human-in-the-loop HVAC systems are gaining attention. This helps in reducing unnecessary energy consumption and also furnish the user with comfortable zones without human interference. The study was carried out in two areas of human dynamics firstly the user centric operations of the HVAC system, in which a five-tier hierarchical taxonomy was based on comfort-driven and occupancy human-in-the-loop HVAC operations. Operations included occupancy detection and comfort. The performance was categorized and quantitatively assessed. In accounting the comfort and occupancy, different methods for sensing techniques were adopted in the HVAC operations. Different particular 
simulations were evaluated and were used to assess results, their viability and challenges. Secondly the Hype cycle model was used. It was used to qualitatively assess the various kinds of technologies used in human-in-the-loop HVAC operations. Results showed that occupancy reactive operations would result in the energy saving of only $15 \%$ where as $6 \%$ median could be achieved by occupancy predictive operations. Even a $20 \%$ energy saving median was available with comfort-aware HVAC. Arumugam Palanivel et al.6thermal behaviour of an brushless direct current motor was analysed and the performance were tested. The DC motor was having corroded magnets. The software used for the analysis was "SPEED". The motor used are popularly used for the electric vehicle propulsion and are clubbed with transaxle having a fixed gear ratio for working. These types of motor are speed sensitive and small change in the speed will change the rotation of the wheel. The corrosion on the magnet affects the speed as flux density changes. It was seen that when the magnet surface was reduced by $0.15 \mathrm{~mm}$ it would result in efficiency loss of $8 \%$ and loss in speed by $70 \mathrm{rpm}$. The torque demand generated heat. As the torque increased the heat also increased around the winding which was because of the increase in current. When high current was applied to the motor for high torque demand the expected torque are not reached because of the magnetic flux density losses. Thermal analysis revealed that the hall element and the stator are affected by the increased heat. The heat was not excessive to change the physical properties of the magnet. B. Melka et al.7 numerically depicted air flow and heat transfer within and outside the casing in a permanent magnet brushless DC motor. In the analysis of heat transfer conditions such as conduction and heat origins like bearings, windings, magnets, forced and natural convection, radiation within internal and external air was included. The analysis was validated on the temperature fields and velocity fields. Seven fixed temperature anemometers were used to record the data above the motor housing at 4 levels. Laser doppler anemometery sensors, 25 thermocouples were fixed outside the motor as well as inside. 4 load conditions and 3 rotational speed were used for the experimental. Error in the temperature were $9 \mathrm{~K}$ for internal and $2 \mathrm{~K}$ for external sensors.

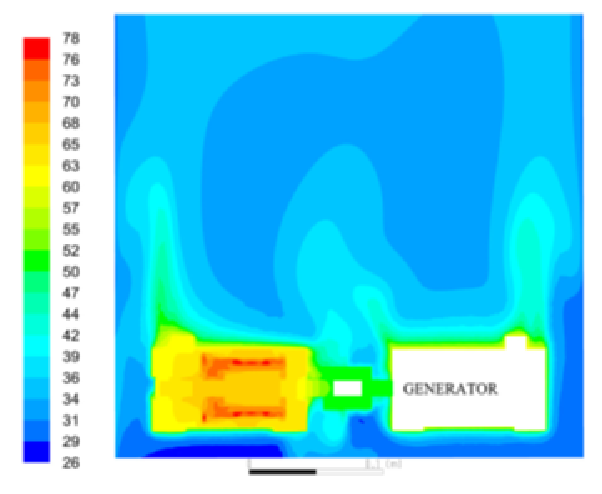

Figure 4: Temperature Display of Motor7

The sensors recorded the temperature on winding region, had the highest temperature of $78^{\circ} \mathrm{C}$. End caps had the highest air temperature and the back-end cap also had the highest air temperature. Vicente Climente-Alarcon et al.8 studied about the electric motor and the effect of thermal stresses on the rotor cage. Defects in rotor cage shortens the operational lifetime. In this thermal analysis a bar breakage was achieved. A model having a combination of mechanical, electrical and thermal was used which were having 3 different meshes which would reflect the progressing narrowing for the end ring to the junction in the bar. The result showed that the increase in damage are proportional to the stress level and agrees with the stator measurement. 


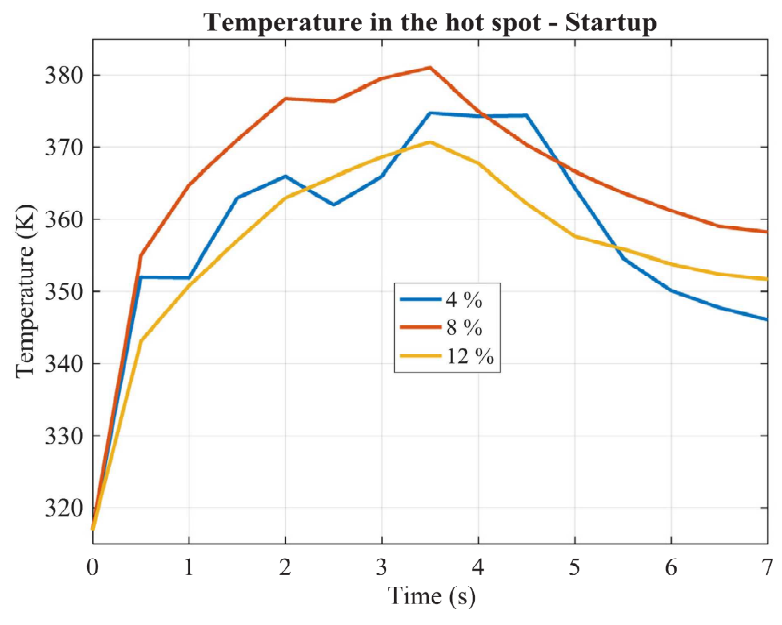

\section{Figure 5: Temperature Change at Startup Transients in the Hot Spot Evolution8}

The evolution of the temperature line showed the hot spot during the starting for cold conditions. The temperature raised from $370.7 \mathrm{~K}$ for $12 \%$ reduction of bar section to $378.7 \mathrm{~K}$ for $8 \%$. When the fault was $4 \%$ the temperature changed to $374.8 \mathrm{~K}$ and this was maintained for 3.5-4.5s, but the pattern was irregular. Lukasz Warguła et al.9examined the stepper motor and its characteristics. The results from the examination would help to evaluate if the stepper motor could be used as generator for the actuator of a periodically variable motion. Gear, cogbelt and chain transmission are examples of periodically variable motion of a mechanical generator. The work is complex and could be completed by manufacturing gear wheels which are designed in good order. The examination results revealed that the stopping and starting time of the stepper motor are different when loaded with torque but are not dependant on the rotational speed, maximum torque obtained and the different type of step control.

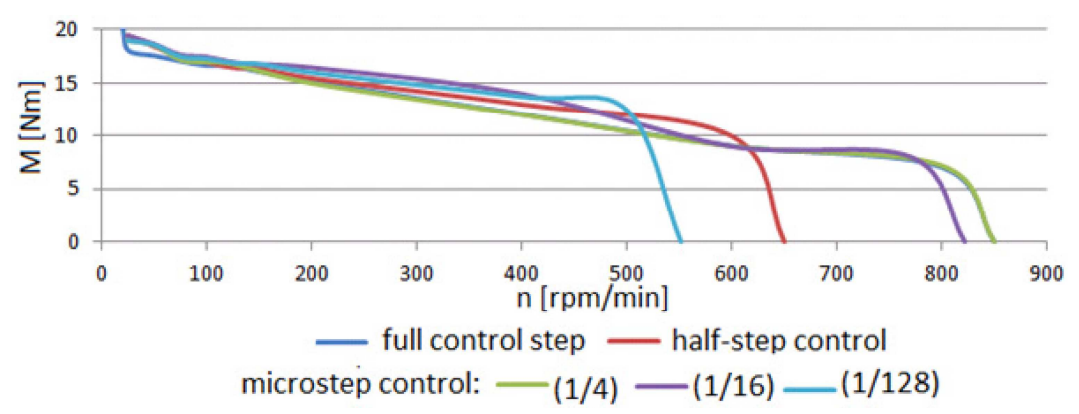

Figure 6: Torque and Speed Relation on
Different Stepper Motor Control9

It was also observed when the rotational speed were high the torque was low till the motor stops for load equal to zero. Microsteps of 1/128 helped to the lowest rotational speed. With microsteps of $1 / 4$ and full-step control it was able to achieve highest value of maximal speed. Maximal speed obtained by the half-step control was lower than achieved by microstep of 1/16, which was higher. As type of step control and maximal rotational speed does not have any relationship it was assumed that those were because of the temperature of the step motor. As the motor operated stepwise it creates some vibration at low speeds. This exists because of the inertia of the axle load and the rotor. Smoothness of the work is achieved the segmentation of steps to microsteps which helps to increase revolution. Microsteps also helps to reduce input energy as the input are pulse inputs which also conduces motor resonance. Mateusz Kukla et al.10 researched about the stepper motor and its torque characteristics. Stepper motor are used for the conversion of the electrical signals into pulses 
for angular rotation. The relationship between the electric signal and the frequency of control impulses are proportional. Development of glue distributing machine was a research concern. For that a prototype was necessary. The work of the glue machine was to glue seats and parts which are used in mass transit vehicles and machines. Parts had complex geometry and different variety that had to be glued. The requirement of proper glue layer and good quality and had to be done in the shortest time, it was required to use control system.

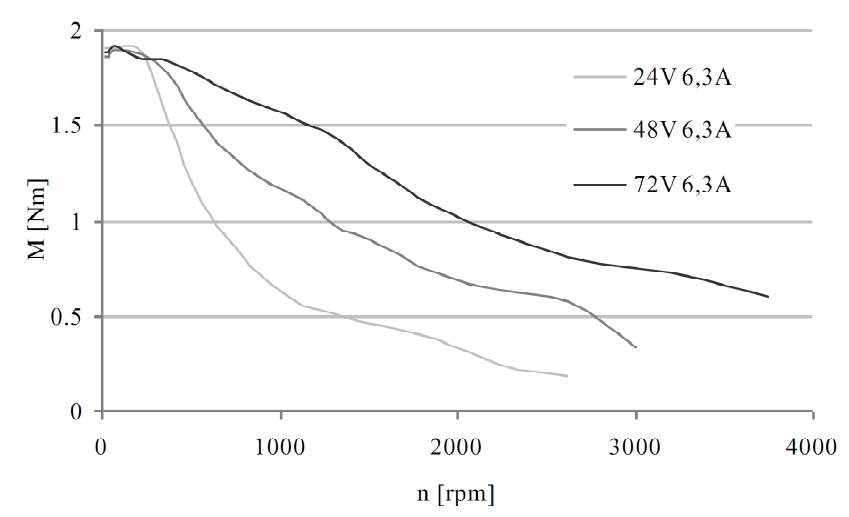

Figure 7: Stepper Motor Mechanical Characteristics10

The results discussed about the different supply current values for the variation in torque was determined. A stepper motor combines maximal torque with the rotational speed, becoming an important mechanical characteristic. It was found that with the increase in the rotation speed the torque decreased. Characteristics showed more values for rise in the current intensity. It was clearly observed that the increase in current intensity was directly connected to the rise in maximal static moment. Stepper motor will always have a static moment value, without induction. The values measured were optimal for the operation of the gluing device. Mohamed Zribi et al.12researched about the permanent magnet stepper motor. Discussion on sliding mode control was carried out from differentially flat systems perspective. Alternating dynamic and static discontinuous feedback control are naturally allowed for de-coupling, flat systems. The approach at the same time was to adjust the dynamic extensions of the systems. For non linear controllable systems dynamic multivariable sliding mode was proposed by the natural results of the flatness of the system. The sliding mode controllers are endogenous which facts about the contributed bonus, flatness of the system were restored. This helped in developing a setup which elaborated the developed theory. Kok-Meng Lee et al. 13presented a conceptual design of a stepper motor which was spherical for robots wrist motor. The motor was having a single joint with 3 degree of freedom. The application of spherical wrist motor had a lot of potential. The end effectors had to be oriented at high speed and was required in all directions. Micro-assembly, laser cutting and laser cutting are some of the application. Variable reluctance stepper motor was the basic on which the spherical motor was developed. Operational difference between the conventional stepper motor and 3 degree of freedom spherical motor was highlighted. The dynamic and kinematic relationships were exhibited with discussing about the torque prediction. $0.44 \mathrm{Nm}$ of maximum restoring torque could be predicted from the preliminary experiment from a pair of Neodymium permanent magnets. The torque was calculated on a rotor of $125 \mathrm{~mm}$ diameter, with increase in size of the magnets or m.m.f of the coil would increase the restoring torque. The spherical stepper wrist motor, optimal design was not complete. Computer simulation and prototype development and experimental validation was being done. The prototype were developed to assist in optimum design. For achieving 3 degree of freedom multiple permanent magnets had to be arranged. Moussa Bendjedia et al.14experimented about the hybrid stepper motor to find the position control without using the mechanical sensors. Mechanical variables were estimated of the motor by the use of steady state 
extended Kalman filter. Computing time came down by use of this method and did not exceed $90 \mu \mathrm{s}$, enabling a $100 \mu \mathrm{s}$ sampling period. Impulse voltage technique was used to estimate the initial rotor position. A simple feedback control was used for the position control, this could counterbalance the torque load variation. Studies on motor parameters variation against robustness was carried out. Simple position feedback are associated with steady-state extended Kalman filter which would compensate the load torque and cancel out the static error. Electronic card were made and gave good design and results were incurred. Proper estimates could be made by good entries making it possible by having proper dimensioning of the voltage filter and current. Stator resistance are system parameters and are an extension of the filter, sensor less controls robustness are improved. Real time estimation of the stator resistance was possible when computing time was reduced. DSP or FPGA implementation was the final objective. Michael Defoort et al.15studied the stepper motor and the control problems where the motor subjected to parameters. Third order sliding mode was used for the development of an algorithm so that the accurate tracking of angular motor position. In the proposed scheme, motor speed and acceleration were estimated or measured for feedback.

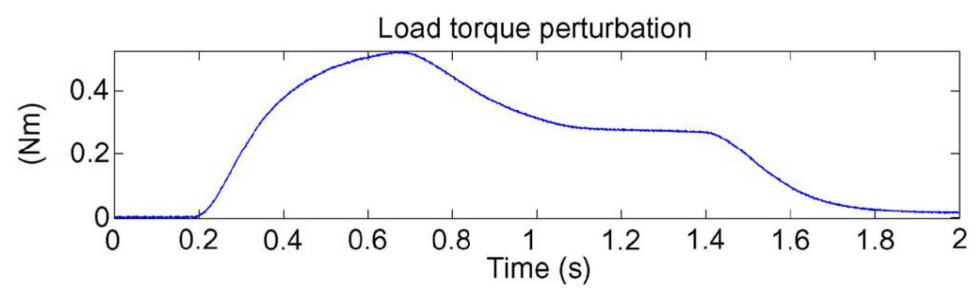

Figure 8: Load Torque Behavior 15

Robust second-order sliding modes was used to reduce the cost and energy consumption by use of tachometer and accelerometer. Advantages and performance of the controller that was proposed was illustrated in the result. It was observed that the consumed power could be reduced when compared with a SMC scheme of second order. The load torque variations were efficiently corrected by the controller. Andrew Kusiak et al.16 studied the HVAC system and energy consumption of the HVAC was minimized by applying data-driven approach. The thermal comfort of the building was maintained with uncertain occupant level. Time series with multilayer perceptron model was used for finding the energy consumption of heating ventilation air conditioning system. Poisson's distribution was used for modelling the arrival rate and for the departure rate uniform. The stochastic process was used calculating the internal heating gain of the building occupancy.

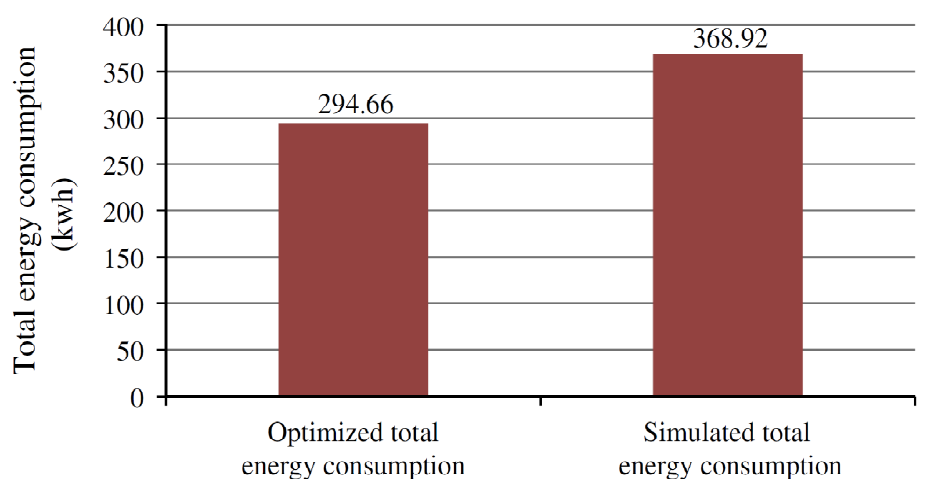

Figure 9: Simulated TEC Compared with Optimized TEC16

Multilayer perceptron algorithm was employed on the simulated data and observation which were used to simulate the HVAC system. HVAC systems future performance was predicted accurately by the data driven models, in 
which the HVAC was based on control settings. Interior point method was used to solve and formulate the optimization model. Heating ventilation air conditioning energy consumption was optimised by the proposed numerical results. Maintaining the comfort level $20.15 \%$ of energy saving was achieved. P. R. Ouyang et al.17reviewed about the micro motion systems which were used both in industry and academics. Micro motion were classified into four types according to the range of motion. Firstly $<1 \mu \mathrm{m}$, secondly $1 \sim 100 \mu \mathrm{m}$, thirdly $100 \sim 1000 \mu \mathrm{m}$, and fourthly $>1000 \mathrm{~m}$. The review summarised that the piezoelectric actuation element when combined with complaint mechanism gave the assuring technology, giving highest accuracy in 4 range of motion. Concept of complaint mechanism was used which based on amplifying technology. Piezoelectric actuation had limited stroke and amplification mechanism was used for compensation of the problem. Increased stiffness and more resolution were achieved with the help of compliant amplification mechanism. Accuracy was not compromised because of the motion amplification. Economically available were the complaint mechanism and the piezoelectric actuation. When needed $1-100 \mu \mathrm{m}$ accuracy in the micro-motion application, recommended motors are dc motor and stepper motor. They are recommended for $>1 \mathrm{~mm}$ motion range application. In case of high acceleration are required in application DC motor and stepper motor produce more heat. It was found that when accuracy, payload and speed were considered the piezoelectric actuator were cheaper, than the stepper motor and the DC motor. Huazhen Fang et al.18studied the design of HVAC control system and deployment of optimal actuator and sensor. It was studied for the improvement of the performance and the temperature monitoring in the building. The strategy for the development was based on maximizing the controllability and observability based matrics. The desired actuator and sensor location have maximum yield with Gramian-based metrics. The paper solution was better than previous work and had following benefits. Firstly, the development of an analytical closed form solution. Secondly the cost of computation was low in an approach which would be practical in use. Lyapunov equation solution was used. To handle spatial constraints, an improved version in the possible locations was proposed. The improved version avoided cluster deployment of the actuators and the sensors so was better appeal, which improved the performance and estimation. Real world situation were obtained by the optimal sensor deployment. Jasper De Viaene et al.19 studied the dynamic stepping motor, its load angle estimation for motion application. Stepping motor are used where there are low power and open loop positioning. Whenever the pulse were send the correct stator phase were exited by the stepping motor driver which would revolve the rotor to a fixed angle position. Open loop positioning, step command pulses counting. In case of stuck or overloaded motor there is loss of step. Because of this the rotors actual position and expected position are lost. Step loss are not detected by majority of the open loop stepping motors. Applications were the stepper motor are used close to its operating boundaries the probability of step loss are high. The over all cost would increase if mechanical position sensor are used to observe the loss in step. Because of the cost a sensor less load angle estimator are used to present the angular domain which is based on the technique of transfer function analyser. Systems capability were reflected by the load angle which indicates the robustness against the disturbances of torque. Tuning was not needed on the algorithm \& could be used with full stepping, half stepping and micro stepping algorithm. One voltage, one current measurement is only needed for the estimation algorithm, and to estimate the load angle electrical parameter is needed. Christian Belly et al.20studied about inertial stepping motor and the benefits of amplification. In high precision application inertial stepping motors are majorly used, for micro manipulation and scanning tunnelling microscopy. When high resolution and long strokes are required simultaneously ISM are used because of they can reach high resolution. The drawback of this technology was the limited speed. The paper used amplified actuator in an ISM to overcome the drawback instead of classical direct actuator. From the electrical current and speed point of view, impact was studied. Analytical way was used to determined the actuator 
stroke to optimise the control signals by the step size of an ISM. The potential limitations were identified by the results that were presented to a lumped model. Three piezoelectric actuators of different types were built a test bench to obtain experimental feedback about the actuator amplification of ISMs benefit. In the case of inertial stepping motor there was good impact of amplification on current consumption and step size. The performance was better for the amplified actuator in comparison to the direct actuator. The amplification was not considered ideal as it had limitations, especially with small actuator stiffness. Pawel Tarkowski et al. 22presented the efficiency of power on the stepper motor, influenced by the acceleration type. The start of the stepper motor at full load was to confirm the nonlinear characteristics efficiency of frequency increase was the main aim. During the start of the stepper motor the commonly used characteristics were talked about and non linear characteristics was proposed. The results were compared with the total angular acceleration criteria. For the acceleration characteristics, torque speed characteristics actual data was obtained from the stepper motor. This method was applied for gluing complicated geometry by machine. Productive time were reduced by using non-linear characteristics. By comparison of the two types of acceleration in stepper motor, achieving the speed took different time was observed. Ratio of $\mathrm{r} 1 / \mathrm{r} 2=1$ showed more time, function of steps characteristics of motor impetus. Acceleration had high value for the frequency increment in the last phase which ended in loosing step phenomena. When $\mathrm{r} 1=0$ parameter was used for characteristics frequency variation, it showed higher speed of rotation with linear frequency increment. In the end phase of acceleration there was less frequency variation. This helped in selecting the best input for the operation of the machine, which would provide motor operation without any trouble. Sergey Edward Lyshevski23 discussed the use of permanent magnet stepper motors for the control of motion in a electromechanical servo-device. Servo-system when actuated by stepper motor had a problem of synthesizing nonlinear controller. Electric machinery was used for the robust design approach and the idea was restricted to permanent magnet stepper motor. Lyapunov-based design was embedded. Introduction of nonlinear control algorithm was carried out, exploration of nonlinear mapping concept. The parameters of the stepper motor were researched and validated for the accuracy of the results. robust control methodology was applied to ensure the stability, offering a new target to study the problem of motion control. Analysis of the performance, efficiency and applicability was explored for presented idea. Experimental verification of the analytical results was carried of the robust tracking and disturbance rejection. Permanent magnet stepper motor could achieve the micro-stepping feature with the synthesised controller and software-hardware developed platform. I Kusunoki et al.24developed a stepping motor to operate ultra-high vacuum. The stepping motor had dry ball bearing and were bakeable till $200^{\circ} \mathrm{C}$, and the stepper motor had $0.72^{\circ}$ step angle, with five phases. Stainless steel was used for the motor casing \&polyimide-insulating wiring was used for coil. To reduce the generated heat from the operated vacuum, it was run at $30 \%$ of normal rating. The performance characteristics were similar to that of a standard motor. Mass spectrometer was used to analyse the outgassing from the stepper motor. When the motor was at rest condition the outgassing was negligible but with increase in speed there was proportional increase in pressure during operation. Results from the mass spectrometer revealed that $\mathrm{H}_{2}, \mathrm{CO}, \mathrm{H}_{2} \mathrm{O}$ and $\mathrm{CO}_{2}$ were released. The most part of the gas was released from the bearings. It was observed that the stepper motor was suitable for Ultra high vacuum.

\section{CONCLUSIONS}

This is a review paper, and it focused on the use of stepper motor in blend door actuator of automotive heating, ventilation and air conditioning system. During the review, it was noticed that stepper motor had many benefits. Heating ventilation air conditioning energy consumption was optimized by the proposed numerical results. Maintaining the comfort level $20.15 \%$ of energy saving was achieved. HVAC system gave better ambient temperature and helped in energy saving. 
And in the case of automotive HVAC system, it provided improved the efficiency of the electric vehicle. As the HVAC system have actuators and in automotive vehicles the blend door is actuated by a actuator. Therefore in general the actuator use DC motor, but if stepper motor are implemented it would result in better performance. Following conclusions were drawn from different researchers.

- The smoothness of the work was achieved by the segmentation of steps to microsteps by stepper motor, which helps to increase revolution. Microsteps also helps to reduce input energy as the input are pulse inputs which also conduces motor resonance.

- Stepper motor will always have a static moment value, without induction and was suitable for precession work because of its torque characteristics.

- It was also noted that consumed power could be reduced when compared with a SMC scheme of second order and the load torque variations were efficiently corrected by the controller for the stepper motor.

- In inertial stepping motor there was good impact of amplification on current consumption and step size. The performance was better for the amplified actuator in comparison to the direct actuator.

- Permanent magnet stepper motor could achieve the micro-stepping feature with the synthesized controller and software-hardware developed platform.

- Thermal analysis of a brushless direct current motor revealed that the hall element and the stator are affected by the increased heat. but the heat was not excessive to change the physical properties of the magnet.

- consumed power could be reduced when compared with a SMC scheme of second order and the load torque variations were efficiently corrected by the controller

- The improved version avoided cluster deployment of the actuators and the sensors so was better appeal, which improved the performance and estimation. Real world situation were obtained by the optimal sensor deployment

- The performance characteristics were similar to that of a standard motor. Mass spectrometer was used to analyse the outgassing from the stepper motor. When the motor was at rest condition the outgassing was negligible but with increase in speed there was proportional increase in pressure during operation. Results from the mass spectrometer revealed that $\mathrm{H} 2, \mathrm{CO}, \mathrm{H} 2 \mathrm{O}$ and $\mathrm{CO} 2$ were released. The most part of the gas was released from the bearings. It was observed that the stepper motor was suitable for Ultra high vacuum.

From the above features of the stepper motor, it was concluded that the stepper motor could be a good alternative of a dc motor. As the stepper motor has good precision and accuracy. The need of a feedback system also could be avoided by the use of a stepper motor. Though the heat generation was similar to a dc motor. But in comparison to the dc motor it has better features and implementation of a stepper motor in the blend door actuator of a HVAC system would be a good alternative.

\section{ACKNOWLEDGMENT}

This work was supported by the Technological Innovation R\&D Program (No: S2518003) funded by the Small and Medium Business Administration (SMBA, Korea) 


\section{REFERENCES}

1. Janocha Hartmut. (2004). Actuators Basics and Applications. New York: Springer

2. Brian Nesbitt. (2007). Handbook of Valves and Actuators. United Kingdom: Elsevier Ltd.

3. Muhammad H. Rashid. 2018. Power Electronics Handbook, Fourth Edition. United Kingdom: Elsevier Inc.

4. Kiran R. Kambly, Thomas H. Bradley. (2014) "Estimating the HVAC energy consumption of plug-in electric vehicles". Journal of Power Sources. 259.117-124

5. Wooyoung Jung, Farrokh Jazizadeh. (2019). "Human-in-the-loop HVAC operations: A quantitative review on occupancy, comfort, and energy-efficiency dimensions" Applied Energy. 239. 1471-1508

6. Arumugam Palanivel, Sutha Padmanabhan. 2018. "Software-based performance estimation and real-time thermal analysis of brushless direct current motor with corroded permanent magnets". Computers and Electrical Engineering. 71. 938-952

7. B. Melka, J. Smolka, J. Hetmanczyk, Z. Bulinski, D. Makiela, A. Ryfa. 2018. "Experimentally validated numerical model of thermal and flow processes within the permanent magnet brushless direct current motor" International Journal of Thermal Sciences. 130. 406-415

8. Vicente Climente-Alarcon, Antero Arkkio, Jose Antonino-Daviu. 2019. "Study of thermal stresses developed during a fatigue test on an electrical motor rotor cage” International Journal of Fatigue. 120. 56-64

9. Lukasz Warguła, Piotr Krawiec, Jarosław M. Adamiec, Konrad J. Waluś. 2017. “The investigations of dynamic characteristics of a stepper motor" Procedia Engineering. 177. 318 - 323

10. Mateusz Kuklaa, Pawet Tarkowski, Ireneusz Malujda, Krzysztof Talaśka, Jan Górecki. 2016. "Determination of the torque characteristics of a stepper motor". Procedia Engineering. 136. 375 - 379

11. Sharma, A. K., Kumawat, R. K., \& Sharma, A. K. (2014). Simulation Of Ac To Ac Converter Fed Induction Motor For Fault Detection And Reduced Harmonic Content. International Journal of Electrical and Electronics Engineering Research, 4(5), $53-62$.

12. Mohamed Zribi, Herbertt Sira-Ramirez, Andy Ngai. 2013. "Static and dynamic sliding mode control schemes for a permanent magnet stepper motor" INT. J. CONTROL. VOL. 74, NO. 2, $103-117$

13. Kok-Meng Lee, George Vachtsevanos, Chikong Kwan. 1988. "Development of a Spherical Stepper Wrist Motor" Journal of lntelligent and Robotic Systems. 1.225-242.

14. Moussa Bendjedia, Youcef Ait-Amirat, Bernard Walther, Alain Berthon. 2012. "Position Control of a Sensorless Stepper Motor" IEEE Transactions On Power Electronics, Vol. 27. 578-587

15. Michael Defoort, Frederic Nollet, Thierry Floquet, Wilfrid Perruquetti. 2009. A Third-Order Sliding-Mode Controller for a Stepper Motor" IEEE Transactions On Industrial Electronics. VOL. 56. 3337-3347

16. Andrew Kusiak, Guanglin Xu, Zijun Zhang. 2014. "Minimization of energy consumption in HVAC systems with data-driven models and an interior-point method" Energy Conversion and Management. 85. 146-153

17. P. R. Ouyang, R. C. Tjiptoprodjo, W. J. Zhang, G. S. Yang. 2008. "Micro-motion devices technology: The state of arts review”. Int J AdvManuf Technol. 38. 463-478

18. Huazhen Fang, Ratnesh Sharma, Rakesh Patil. 2014. "Optimal Sensor and Actuator Deployment for HVAC Control System Design" American Control Conference. 2240-2246 
19. Jasper De Viaene, Stijn Derammelaere, Kurt Stockman. 2018. "Load angle estimation for dynamic stepping motor motion applications" Mechatronics. 53. 229-240

20. Christian Belly, Willy Charon. 2012. “Benefits of amplification in an inertial stepping motor” Mechatronics. 22. 177-183

21. Sures, H. Fortification and culpability Analysis of Three Phase Induction Motor using Labview.

22. Pawet Tarkowski, Ireneusz Malujda, Krzysztof Talaśka, Mateusz, Kukla, Jan Górecki. 2016. "Influence of the type of acceleration characteristic of the stepping motor for efficient power usage”. Procedia Engineering. 136. 370 - 374

23. Sergey Edward Lyshevski. 1997. "Motion Control of Electromechanical Servo-Devices With Permanent-Magnet Stepper Motors". Mechatronics. Vol. 7. 521536

24. I Kusunoki,H Satomi, M Kobori, H Domeki. 1990. "Stepping motor for use in uhv" Vacuum. 41.pages 1946-1947 
